\title{
Simulation of the sporadic $E$ layer response to prereversal associated evening vertical electric field enhancement near dip equator
}

\author{
A. J. Carrasco, ${ }^{1,2}$ I. S. Batista, ${ }^{2}$ and M. A. $\mathrm{Abdu}^{2}$ \\ Received 27 October 2006; revised 13 March 2007; accepted 30 March 2007; published 22 June 2007.
}

[1] The role of the molecular and metallic ions in the formation of sporadic $E$ layers

(Es layers) has been an active area of research for many years. Ionosonde data of

the Es layer parameter, fbEs (the blanketing frequency of sporadic layer), and ftEs (the top frequency of Es trace), obtained over the Brazilian sites, Fortaleza, and São Luis, show that the diurnal variations of these parameters often present a disruption that is coincident with the evening prereversal electric field/vertical drift enhancement, to reappear after about 2 hours. In this work we have developed a model of the $E$ region with the objective to describe all the phases of the life cycle of the sporadic layer and its relation to the evening vertical electric field enhancement that is associated with the development of the prereversal zonal electric field enhancement. The model calculates the densities of $\mathrm{NO}^{+}$, $\mathrm{O}_{2}^{+}, \mathrm{O}^{+}, \mathrm{N}_{2}^{+}$, and $\mathrm{Fe}^{+}$in the height region $86-140 \mathrm{~km}$ by simultaneously solving the continuity and momentum equations for each of the species. For low latitudes this model shows that winds and electric fields each play distinct roles in the vertical transport of plasma leading to $E s$ layer formation. The results of our numerical simulation confirm the dominant role of the vertical electric field as the cause of the inhibition/disruption of the sporadic layer in the evening. More specifically, the results reveal that an upward directed (positive) vertical electric field is capable of disrupting an ongoing sporadic layer, whereas a downward (negative) electric field favors its formation or even intensification, thus corroborating the conclusions of the recent study by Abdu et al. (2003).

Citation: Carrasco, A. J., I. S. Batista, and M. A. Abdu (2007), Simulation of the sporadic E layer response to prereversal associated evening vertical electric field enhancement near dip equator, J. Geophys. Res., 112, A06324, doi:10.1029/2006JA012143.

\section{Introduction}

[2] Sporadic $E$ layers (Es layers), also known as tidal ion layers, have been studied for more than 50 years using a wide range of diagnostic techniques, notably by radars and ionosondes and to a lesser degree by sounding rockets and by satellites [Narcisi, 1967; Smith, 1970; Shen et al., 1976; Miller et al., 1993; Kopp, 1997; Heelis, 1999]. The Es layers appear as thin layers $(\sim 5-10 \mathrm{~km}$ vertical thickness $)$ of plasma density enhancements above the background $E$ layer density. They are often seen descending from the bottomside of the $F$ region to below $100 \mathrm{~km}$ over the course of several hours [see, e.g., Haldoupis et al., 2006]. Ion composition studies of the $E$ region using sounding rockets consistently reveal the presence of metallic species, such as $\mathrm{Fe}^{+}, \mathrm{Mg}^{+}$, $\mathrm{Ca}^{+}$, and $\mathrm{Na}^{+}$, with relatively more abundance of $\mathrm{Fe}^{+}$and $\mathrm{Mg}^{+}$[Kopp, 1997]. Such composition studies also have shown that $E s$ layers consist mainly of long-lived metal ions such as $\mathrm{Fe}^{+}$and $\mathrm{Mg}^{+}$. The locally abundant molecular ions of the background $E$ region, $\mathrm{NO}^{+}$and $\mathrm{O}_{2}^{+}$, are actually deficient

\footnotetext{
${ }^{1}$ Departamento de Física, Universidad de Los Andes, Mérida, Venezuela.

${ }^{2}$ Instituto Nacional de Pesquisas Espaciais, São José dos Campos, São Paulo, Brazil.

Copyright 2007 by the American Geophysical Union. 0148-0227/07/2006JA012143
}

in a sporadic $E$ layer [Layzer, 1972; Kopp, 1997]. Because metal ions are atomic species, they can only undergo radiative recombination with electrons and thus have much longer lifetimes that the molecular ions and are more subject to dynamic effects [MacDougall et al., 2000; Aikin and Goldberg, 1973]. The formation of the sporadic layers at higher levels and its subsequent downward movement and change in shape have been interpreted by several authors [e.g., Korenkov, 1979; Carter and Forbes, 1999] in terms of the ionization redistribution by the vertical shear of a horizontal wind at midlatitudes (for the wind shear theory, see Whitehead [1961] and Axford [1963]).

[3] The wind shear theory has received much attention and has been most fruitful in the study of $E s$ layers over middle and low latitudes. According to the simple wind shear theory, an Es layer can occur near the nodal point of vertical shear in the horizontal wind, (meridional or zonal) where the vertical ionization drift, $\mathrm{Vz}$, is zero. In a magnetized plasma at low and middle latitudes, vertical convergence of the charged particles by $\mathbf{U}_{\mathrm{y}} \times \mathbf{B}$ forces occurs with a westward wind above and an eastward wind bellow the nodal point. Here $\mathbf{U}_{\mathrm{y}}$ and $\mathbf{B}$ are the zonal wind and the geomagnetic field, respectively. The sporadic $E$ layer formation by the vertical plasma convergence mechanism due to wind shear can take place even in the absence of any local ion production process, so long as the ambient plasma recombination timescale is larger (slower recombination) than that of the plasma convergence process. 
Thus metallic ions that have significantly slower recombination rate are generally more abundant than molecular ions in the composition of the sporadic $E$ layers.

[4] After the first publication of the observational results by Abdu et al. [1996], showing the disappearance of Es layers in the ionograms at the evening $F$ layer vertical uplift over Fortaleza, additional results with supporting evidences were presented by $A b d u$ et al. [2003] who also proposed a mechanism to explain the observed phenomenon. This mechanism connects the development of the evening prereversal zonal electric field/vertical drift enhancement to the Es layer disappearance/disruption and later reformation as follows. The development of the evening prereversal electric field (PRE) is a result of the dynamo action of the thermospheric zonal wind, eastward at this time, in the presence of a longitudinal/local time gradient in the $E$ layer conductivity [Rishbeth, 1971; Heelis et al., 1974]. The $F$ region vertical electric field arising from the $\mathbf{U} \times \mathbf{B}$ action of the eastward thermospheric wind has a local time variation (the intensity increasing toward nightside), whose curl-free condition is responsible for the zonal prereversal electric field [Eccles, 1998; Rishbeth, 1971]. This is complemented by an electric field arising from the electrojet current divergence at the sunset terminator as explained by Haerendel et al. [1992]. The net result is an evening vertical electric field height structure over the equator as part of the PRE, which consists of an upward directed electric field in the height region $\sim 90-300 \mathrm{~km}$ reversing to a downward directed field above $\sim 300 \mathrm{~km}$ as obtained at $\sim 1900$ LT (for example) in the model results by Haerendel et al. [1992] which is also consistent with the postsunset plasma flow vortex pattern observed over Jicamarca radar by Kudeki and Bhattacharyya [1999]. When this electric field is field-line mapped to offequatorial latitudes we have an upward directed electric field over Fortaleza $\left(3.8^{\circ} \mathrm{S}, 38.0^{\circ} \mathrm{W}\right.$, dip angle $\left.=-10.9^{\circ}\right)$ and a downward directed electric field at a location farther away in latitude, such as Cachoeira Paulista $\left(22.4^{\circ} \mathrm{S}, 45.0^{\circ} \mathrm{W}\right.$, dip angle $=-31.8^{\circ}$ ). Such a situation, as explained by $A b d u$ et al. [2003], could lead to the disruption of Es layer formation over Fortaleza with uninterrupted, or even enhanced, Es layer formation over Cachoeira Paulista. This mechanism, though qualitative in nature, appears to be consistent with the observational data. A quantitative evaluation of this mechanism is attempted in this paper. Our main objective here is to simulate the Es layer disruption in evening over the station Fortaleza. We will investigate the influence of the $F$ region vertical electric field on the development of Es layer around the local evening hours over Fortaleza using a numerical model. The photochemistry of the model includes all the major molecular ion species as well as the most dominant metallic ion $\mathrm{Fe}^{+}$. The mathematical model for $E$ region is described in section 3 and it yields as output the concentrations of $\mathrm{NO}^{+}, \mathrm{O}_{2}^{+}, \mathrm{O}^{+}, \mathrm{N}_{2}^{+}$, and $\mathrm{Fe}^{+}$. The main difference of this model in comparison with other mathematical models used to simulate Es layers is that our model takes into account the effect of the vertical electric field of the equatorial $E-F$ regions in formation of the $E s$ layer.

\section{Experimental Results}

[5] The observational results on $h^{\prime} F$ (the $F$ layer base virtual height) and fbEs (blanketing frequency of sporadic
$E$ layer) to be analyzed in this study were obtained from the processing of ionograms obtained from the ionospheric stations: São Luís $\left(2.3^{\circ} \mathrm{S}, 44.0^{\circ} \mathrm{W}\right.$, dip angle $\left.=-1.5^{\circ}\right)$, Fortaleza $\left(3.8^{\circ} \mathrm{S}, 38.0^{\circ} \mathrm{W}\right.$, dip angle $\left.=-10.9^{\circ}\right)$, and Cachoeira Paulista $\left(22.4^{\circ} \mathrm{S}, 45.0^{\circ} \mathrm{W}\right.$, dip angle $\left.=-31.8^{\circ}\right)$. The magnetic dip for these stations was determined using the International Geomagnetic Reference Field (IGRF) model. In this study we have presented the variation of the apparent vertical drift of the $F$ region plasma, around sunset, deduced as $V z a=\Delta\left(h^{\prime} F\right) / \Delta t$. During the evening hours, when the equatorial $F$ layer height usually exceeds a threshold height of $300 \mathrm{~km}$, the apparent vertical drift velocity, as measured by an ionosonde, is practically the same as the vertical $\mathbf{E} \times \mathbf{B}$ plasma drift velocity that would be measured by incoherent scatter radar. For heights less than $300 \mathrm{~km}$, the apparent vertical velocity starts to depart significantly from the $\mathbf{E} \times \mathbf{B}$ plasma drift velocity, owing to the increasing dominance of the recombination process at lower heights [Bittencourt and Abdu, 1981; Batista et al., 1986].

[6] Our database consists of 5 days of data in June 2001 $(2,8,9,12$, and 14 June). Figure 1 shows the variation of the mean and the standard deviations for fbEs (Figures 1a, $1 \mathrm{~b}$, and 1c) and $V z a$ (Figures 1d, 1e, and 1f) over the three locations in Brazil. In this figure we may note that fbEs presents an interruption after 1900 LT over São Luís and after the 1930 LT over Fortaleza, with no such interruption occurring over Cachoeira Paulista. From the ionogram observations we note that the Es layer reflection frequency over São Luís and Fortaleza was below the lower limit of detection by the ionosonde $\left(1.5 \mathrm{MHz}\right.$ or $\left.2.8 \times 10^{4} \mathrm{el} . \mathrm{cm}^{-3}\right)$, which means a significant abating of the Es density with duration of $\sim 2$ hours. We denote this condition as "disruption" of the Es layer, although it is not possible to affirm, if the Es layer disappeared totally under that condition. It appears that the physical conditions over São Luís and Fortaleza were favorable for the abating or interruption of the sporadic layer because of the sufficient proximity of these stations to the magnetic equator which was not the case with Cachoeira Paulista [Abdu et al., 2003]. Also we note in this figure that the maximum values of the prereversal vertical plasma drift velocity $(V z p)$ at São Luís and Fortaleza are 40 and $30 \mathrm{~m} / \mathrm{s}$, respectively. The values of $V z p$ can be used to establish a visual relation between this and fbEs. In other words, the interruption in fbEs can occur at latitudes where $V z p$ is high or when the $V z p$ over the equator exceeds a threshold value (as discussed in the work of $A b d u$ et al. [2003]). Also from the $V z p$ we can determine a value approximated for the zonal electric field over these latitudes. As was commented above and will be shown in the next sections the zonal electric field is related to the vertical electric field through the ratio of the field line integrated Hall to Pedersen conductivities. From the important relationship between the two electric field components, we can establish a connection between the postsunset Es layer interruption and the electrodynamic processes that generate the prereversal enhancement in the vertical plasma drift of the $E$ and $F$ region.

\section{Basic Equations of the Ionospheric Model}

[7] A numerical simulation of sporadic $E$ layers was carried out by modeling the ion density development in a 

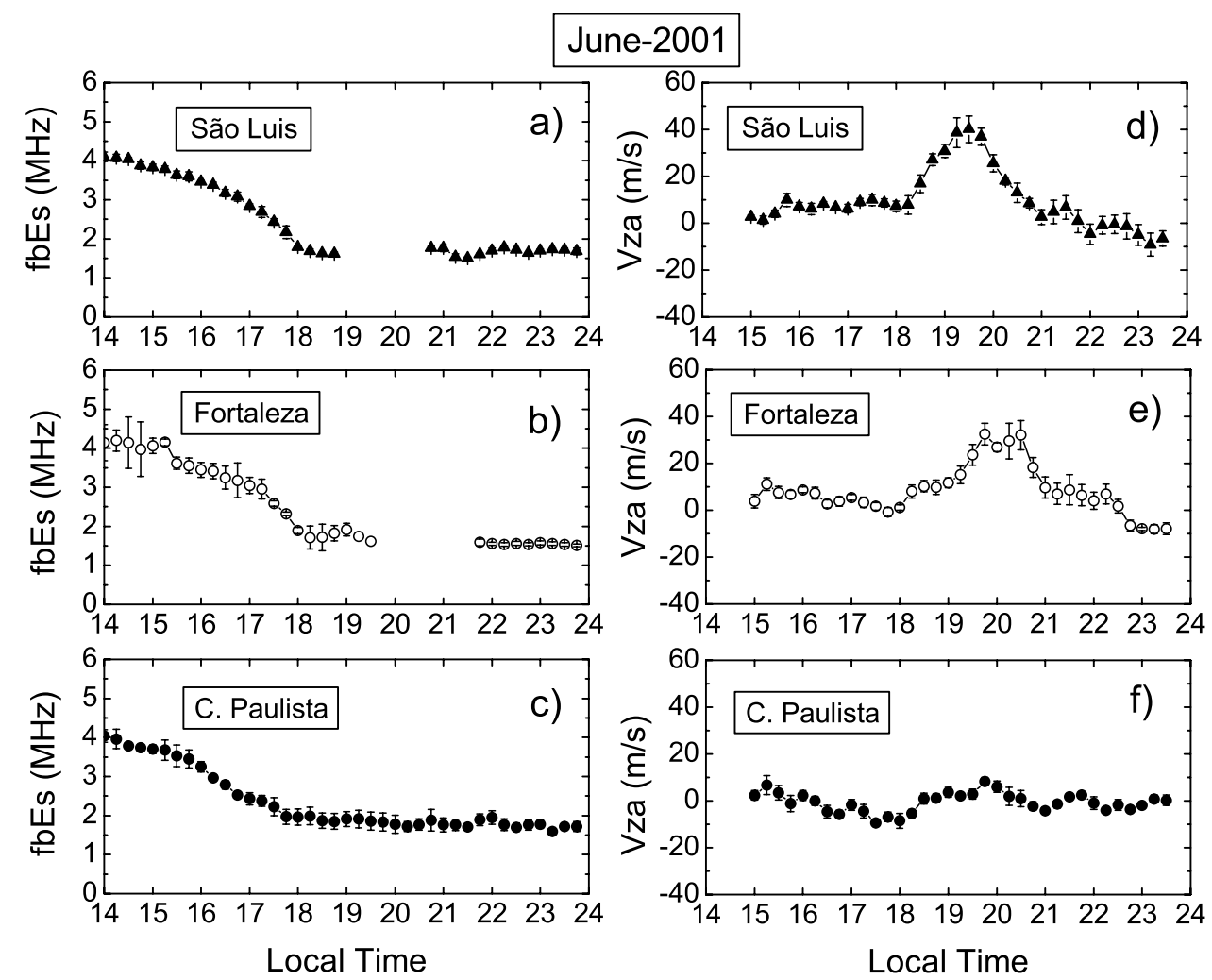

Figure 1. Mean values for (left) fbEs and (right) Vza over three locations in Brazil for June 2001 (the vertical bars represent the standard deviations).

height region between 86 and $140 \mathrm{~km}$ using a system of coupled continuity and momentum equations for the species $\mathrm{NO}^{+}, \mathrm{O}_{2}^{+}, \mathrm{O}^{+}, \mathrm{N}_{2}^{+}$, and $\mathrm{Fe}^{+}$. The systems of mathematical equations which describe the known physical and chemical processes are nonlinear and special numerical techniques are required for their solution. The chemical reactions and the respective rate constants used in the $E$ region model are given in Table 1 for molecular ions [Chen and Harris, 1971] and Table 2 for metallic ions [Carter and Forbes, 1999]. The continuity equations used for the five ionic species are given by:

$$
\begin{gathered}
\frac{\partial\left[\mathrm{O}^{+}\right]}{\partial t}=q_{\mathrm{O}^{+}}-k_{1}\left[\mathrm{O}^{+}\right]\left[\mathrm{O}_{2}\right]-k_{2}\left[\mathrm{O}^{+}\right]\left[\mathrm{N}_{2}\right]-\frac{\partial\left(\mathrm{V}_{\mathrm{O}^{+}}\left[\mathrm{O}^{+}\right]\right)}{\partial z} \\
\frac{\partial\left[\mathrm{N}_{2}^{+}\right]}{\partial t}=q_{\mathrm{N}_{2}^{+}}-k_{3}\left[\mathrm{~N}_{2}^{+}\right][\mathrm{O}]-k_{4}\left[\mathrm{~N}_{2}^{+}\right]\left[\mathrm{O}_{2}\right]-\frac{\partial\left(\mathrm{V}_{\mathrm{N}_{2}^{+}}\left[\mathrm{N}_{2}^{+}\right]\right)}{\partial \mathrm{z}} \\
\frac{\partial\left[\mathrm{O}_{2}^{+}\right]}{\partial t}=q_{\mathrm{O}_{2}^{+}}+k_{1}\left[\mathrm{O}^{+}\right]\left[\mathrm{O}_{2}\right]+k_{4}\left[\mathrm{~N}_{2}^{+}\right]\left[\mathrm{O}_{2}\right] \\
-k_{5}\left[\mathrm{O}_{2}^{+}\right][\mathrm{NO}]-\alpha_{\mathrm{O}_{2}^{+}}\left[\mathrm{O}_{2}^{+}\right] n_{e}-\frac{\partial\left(\mathrm{V}_{\mathrm{O}_{2}^{+}}\left[\mathrm{O}_{2}^{+}\right]\right)}{\partial z} \\
\frac{\partial\left[\mathrm{NO}^{+}\right]}{\partial t}= \\
-q_{\mathrm{NO}^{+}}+k_{2}\left[\mathrm{O}^{+}\right]\left[\mathrm{N}_{2}\right]+k_{3}\left[\mathrm{~N}_{2}^{+}\right][\mathrm{O}]+k_{5}\left[\mathrm{O}_{2}^{+}\right][\mathrm{NO}] \\
-\alpha_{\mathrm{NO}^{+}}\left[\mathrm{NO}^{+}\right] n_{e}-\frac{\partial\left(\mathrm{V}_{\mathrm{NO}^{+}}\left[\mathrm{NO}^{+}\right]\right)}{\partial z}
\end{gathered}
$$

$$
\begin{aligned}
\frac{\partial\left[\mathrm{Fe}^{+}\right]}{\partial t}= & {[\mathrm{Fe}]\left(j_{1}+\left[\mathrm{NO}^{+}\right] \gamma_{13}+\left[\mathrm{O}_{2}^{+}\right] \gamma_{14}+\left[\mathrm{O}^{+}\right] \gamma_{15}\right) } \\
& -\left[\mathrm{Fe}^{+}\right] n_{e} \gamma_{2}-\left[\mathrm{Fe}^{+}\right]\left\{\left[\mathrm{N}_{2}\right]\left(\left[\mathrm{O}_{2}\right] \gamma_{10}+\left[\mathrm{N}_{2}\right] \gamma_{11}+[\mathrm{O}] \gamma_{12}\right)\right\} \\
& -\frac{\partial\left(\mathrm{V}_{\mathrm{Fe}^{+}}\left[\mathrm{Fe}^{+}\right]\right)}{\partial z} \\
& n_{e}=\left[\mathrm{O}_{2}^{+}\right]+\left[\mathrm{NO}^{+}\right]+\left[\mathrm{O}^{+}\right]+\left[\mathrm{N}_{2}^{+}\right]+\left[\mathrm{Fe}^{+}\right]
\end{aligned}
$$

where $n_{e}$ is the electron density and $q_{i}$ is the rates of production due to the solar radiation. The last term in each equation represents the plasma transport. $\mathrm{As}_{2}^{+}$and $\mathrm{O}^{+}$are minor constituents in the $E$ region due to the rapid rate at which they are converted to $\mathrm{NO}^{+}$and $\mathrm{O}_{2}^{+}$and also due to their extremely small nighttime production in the height region 90-150 km, following Chen and Harris [1971], the equations (1) and (2) can be approximated by:

$$
\begin{aligned}
& {\left[\mathrm{O}^{+}\right]=\frac{q_{\mathrm{O}^{+}}}{k_{1}\left[\mathrm{O}_{2}\right]+k_{2}\left[\mathrm{~N}_{2}\right]},} \\
& {\left[\mathrm{N}_{2}^{+}\right]=\frac{q_{\mathrm{N}_{2}^{+}}}{k_{3}[\mathrm{O}]+k_{4}\left[\mathrm{O}_{2}\right]} .}
\end{aligned}
$$

[8] With this simplification the system of five differential equations is reduced to one of three equations. The continuity equations for $\mathrm{O}_{2}^{+}, \mathrm{NO}^{+}$, and $\mathrm{Fe}^{+}$are solved in Cartesian coordinates with $x$ (positive southward), $y$ (posi- 
Table 1. Chemical Reactions for Molecular Ions Species Used in the Model

\begin{tabular}{lc}
\hline \multicolumn{1}{c}{ Reaction } & Value \\
\hline \multicolumn{3}{c}{ Production Rate, $\mathrm{cm}^{-3} s^{-1}$} \\
$\mathrm{O}_{2}+h v \rightarrow \mathrm{O}_{2}^{+}+e$ & $q_{\mathrm{O}_{2}^{+}}$ \\
$\mathrm{N}_{2}+h v \rightarrow \mathrm{N}_{2}^{+}+e$ & $q_{\mathrm{N}_{2}^{+}}$ \\
$\mathrm{NO}+h v \rightarrow \mathrm{NO}^{+}+e$ & $q_{\mathrm{NO}^{+}}$ \\
$\mathrm{O}+h v \rightarrow \mathrm{O}^{+}+e$ & $q_{\mathrm{O}^{+}}$ \\
\multicolumn{2}{c}{} \\
$\mathrm{O}^{+}+\mathrm{O}_{2} \rightarrow \mathrm{O}_{2}^{+}+\mathrm{O}$ & $k_{1}=4.0 \times 10^{-11}$ \\
$\mathrm{O}^{+}+\mathrm{N}_{2} \rightarrow \mathrm{NO}^{+}+\mathrm{N}$ & $k_{2}=1.3 \times 10^{-12}$ \\
$\mathrm{~N}_{2}^{+}+\mathrm{O} \rightarrow \mathrm{NO}^{+}+\mathrm{N}$ & $k_{3}=2.5 \times 10^{-10}$ \\
$\mathrm{~N}_{2}^{+}+\mathrm{O}_{2} \rightarrow \mathrm{O}_{2}^{+}+\mathrm{N}_{2}$ & $k_{4}=1.0 \times 10^{-10}$ \\
$\mathrm{O}_{2}^{+}+\mathrm{NO} \rightarrow \mathrm{NO}^{+}+\mathrm{O}_{2}$ & $k_{5}=8.0 \times 10^{-10}$ \\
$\mathrm{NO}^{+}+e \rightarrow \mathrm{N}+\mathrm{O}$ & $\alpha_{\mathrm{NO}^{+}}=4.7 \times 10^{-7}(300 / \mathrm{Te})$ \\
$\mathrm{O}_{2}^{+}+e \rightarrow \mathrm{O}+\mathrm{O}$ & $\alpha_{\mathrm{O}_{2}^{+}}=2.2 \times 10^{-7}(300 / \mathrm{Te})^{0.7}$ \\
\hline
\end{tabular}

tive eastward), and $z$ (positive upward). The vertical ion velocity for each of these constituents is determined using the following relation:

$$
\begin{aligned}
\mathrm{V}_{i z}= & \frac{\omega_{i}^{2}}{v_{i n}^{2}+\omega_{i}^{2}}\left[\cos I \sin I U_{x}+\frac{v_{i n}}{\omega_{i}} \cos I U_{y}\right] \\
& +\frac{\omega_{i}^{2}}{v_{i n}^{2}+\omega_{i}^{2}}\left[\frac{e}{m_{i} v_{i n}} \cos I \sin I E_{x}+\frac{e}{m_{i} \omega_{i}} \cos I E_{y}\right. \\
& \left.+\frac{e}{m_{i} v_{i n}}\left(\frac{v_{i n}^{2}}{\omega_{i}^{2}}+\sin ^{2} I\right) E_{z}\right],
\end{aligned}
$$

where $\omega_{i}$ is gyrofrequency, $m_{i}$ is the ion mass, $e$ is the ion electric charge, $v_{i n}$ is the collision frequency of ions with neutral, $E_{x}, E_{y}$, and $E_{z}$ are the components of the electric field, $I$ is the magnetic dip, and the horizontal wind components are $U_{y}$ (eastward) and $U_{x}$ (southward). For low latitudes the vertical ion velocity can be approximated by the following expression:

$$
\mathrm{V}_{i z}=\frac{\omega_{i}^{2}}{v_{i n}^{2}+\omega_{i}^{2}}\left[\frac{v_{i n}}{\omega_{i}} U_{y}+\frac{e}{\omega_{i} m_{i}} E_{y}+\frac{e v_{i n}}{m_{i} \omega_{i}^{2}} E_{Z}\right] .
$$

[9] As explained by Abdu et al. [2003], for heights below $120 \mathrm{~km}$ the contribution of $E_{y}$ to the sporadic layer formation becomes negligibly small. Thus at low latitude the sporadic layer formation arising from the vertical shear in $\mathrm{V}_{i z}$ results from the competing roles between $U_{y}$ and $E_{z}$ as per equation (10). We have considered the height region $90-140 \mathrm{~km}$ as this is adequate for our modeling of sporadic $E$ layer over Fortaleza, and our interest is limited to testing the hypothesis for the interruption of the sporadic layer in the evening as due to the vertical electric field structure, proposed by $A b d u$ et al. [2003]. A more rigorous evaluation of sporadic layer disruption and reformation would require detailed measured values of the local time and height structure of $E_{z}$ and $U_{y}$ for the evening equatorial ionosphere. However, such information is lacking, especially for the latitude of Fortaleza. We shall therefore use some available models to determine these parameters and to evaluate their competing influences on the vertical ion convergence in the $E$ region.

\section{Model Inputs}

[10] The solution of the system of equations (3), (4), (5), $(6),(7)$, and (8), would require knowledge of the variations in time and height of certain atmospheric parameters such as the density and temperature of the atmosphere, collision frequency, electric fields, and the height profile of the neutral iron density.

[11] The concentrations of the atmospheric constituents, $\mathrm{O}$, $\mathrm{O}_{2}$, and $\mathrm{N}_{2}$, denoted by $[\mathrm{O}],\left[\mathrm{O}_{2}\right]$, and $\left[\mathrm{N}_{2}\right]$, respectively, and the neutral gas temperature, are obtained from the Mass Spectrometer Incoherent Scatter Extension 1990 (MSISE90) model [Hedin, 1991]. The constituent, NO, is not included in the MSISE90 model; its concentration is calculated from the nitric oxide density model developed by Barth et al. [1996]. The concentration of Fe, denoted as [Fe], is calculated from neutral iron model developed by Helmer et al. [1998]. The theory of this model is described in section 4.1.

[12] In the computation of $V_{i z}$ using equation (10), the collision frequencies of $\mathrm{O}_{2}^{+}$and $\mathrm{NO}^{+}$with neutral particles were obtained from Bailey and Balan [1996] and that of $\mathrm{Fe}^{+}$ with neutral particles from Korenkov [1979]. For the computation of $q_{i}$, the photoionization rate, the solar spectrum was divided into 38 intervals, from 50 to $1216 \AA$. For these intervals, the photoionization and photoabsorption crosssection for $\mathrm{O}, \mathrm{O}_{2}$, and $\mathrm{N}_{2}$ were taken from Rees [1989] and for NO from Turunen et al. [1996]. The diurnal solar EUV fluxes were adopted from EUVAC radiation model by Richards et al. [1994] and the nocturnal solar fluxes from Strobel et al. [1974].

\subsection{Ablation and Iron Density}

[13] In general it is widely accepted that the ablation of meteoroids upon entry into the Earth's atmosphere provides the dominant source for metallic species observed in the upper mesosphere and thermosphere [Carter and Forbes, 1999; Helmer et al., 1998]. According to the classical theory of ablation of meteor particles, the production of metallic atoms is based on the following suppositions: (1) the meteoroids are solid particles, of small radius compared with the mean free path of the air molecules at heights above $70 \mathrm{~km}$; (2) these solid particles are heated through individual collisions with air molecules, and the effects of black body radiation from the surface of the meteoroid as well as the thermal capacity of the meteoroid are small and can be neglected; (3) all the heat received from the collisions with air molecules is assumed to be dissipated by the evaporation of the meteoric substance assumed to starts at infinity; and (4) the relative kinetic energy of an air molecule is sufficient to cause the evaporation of a considerable number of the meteoric atoms, and thus the total mass of air intercepted by the meteoroid before it evaporates completely is small compared with

Table 2. Chemical Reactions for Metallic Species Used in the Model

\begin{tabular}{cc}
\hline Reaction & Rate Coefficient \\
\hline $\mathrm{Fe}+h v \rightarrow \mathrm{Fe}^{+}+e$ & $j_{1}=5.0 \times 10^{-7} \mathrm{~s}^{-1}$ \\
$\mathrm{Fe}^{+}+e \rightarrow \mathrm{Fe}+7.9 e \nu$ & $\gamma_{2}=1.0 \times 10^{-12} \mathrm{~cm}^{3} \mathrm{~s}^{-1}$ \\
$\mathrm{Fe}^{+}+\mathrm{O}_{2}+\mathrm{N}_{2} \rightarrow \mathrm{FeO}_{2}^{+}+\mathrm{N}_{2}$ & $\gamma_{10}=2.5 \times 10^{-30} \mathrm{~cm}^{6} \mathrm{~s}^{-1}$ \\
$\mathrm{Fe}^{+}+\mathrm{N}_{2}+\mathrm{N}_{2} \rightarrow \mathrm{FeN}_{2}^{+}+\mathrm{N}_{2}$ & $\gamma_{11}=2.5 \times 10^{-30} \mathrm{~cm}^{6} \mathrm{~s}^{-1}$ \\
$\mathrm{Fe}^{+}+\mathrm{O}+\mathrm{N}_{2} \rightarrow \mathrm{FeO}^{+}+\mathrm{N}_{2}$ & $\gamma_{12}=2.5 \times 10^{-30} \mathrm{~cm}^{6} \mathrm{~s}^{-1}$ \\
$\mathrm{Fe}+\mathrm{NO}^{+} \rightarrow \mathrm{Fe}^{+}+\mathrm{NO}$ & $\gamma_{13}=7.0 \times 10^{-10} \mathrm{~cm}^{3} \mathrm{~s}^{-1}$ \\
$\mathrm{Fe}+\mathrm{O}_{2}^{+} \rightarrow \mathrm{Fe}^{+}+\mathrm{O}_{2}$ & $\gamma_{14}=9.4 \times 10^{-10} \mathrm{~cm}^{3} \mathrm{~s}^{-1}$ \\
$\mathrm{Fe}+\mathrm{O}^{+} \rightarrow \mathrm{Fe}^{+}+\mathrm{O}$ & $\gamma_{15}=2.0 \times 10^{-9} \mathrm{~cm}^{3} \mathrm{~s}^{-1}$ \\
\hline
\end{tabular}


the mass of the meteoroid [Jones and Kaiser, 1966]. For an isothermal atmosphere the evaporation rate of meteoric atoms, $\delta$, can be represented by the following relation:

$$
\delta=\frac{9}{4} \delta_{m} \frac{\rho_{a}}{\rho_{m}}\left\{1-\frac{1}{3} \frac{\rho_{a}}{\rho_{m}}\right\}^{2}
$$

where $\rho_{a}$ is the air density and $\delta_{m}$ is the maximum rate of evaporation of meteoric atoms which occur at an air density $\rho_{m} \approx 3 \times 10^{-9} \mathrm{~g} \mathrm{~cm}^{-3}(z=90 \mathrm{~km})$. For the case of iron, according to Carter and Forbes [1999], $\delta_{m} \approx 0.008$ atoms $\mathrm{cm}^{-3} \mathrm{~s}^{-1}$.

[14] The number density model for [Fe] used in this work is based on the work of Helmer et al. [1998]. In the work of Helmer et al. [1998] the model developed for [Fe] is based on the following suppositions: (1) the iron injected into the upper atmosphere via meteor ablation processes is transported vertically due to the combined effects of eddy and molecular diffusion, where electrodynamical effects on ionic species can be ignored; (2) in the altitude range 70 to $110 \mathrm{~km}$ the transport processes for the motion of all atmospheric constituents is governed by eddy diffusion; (3) the chemical equilibrium of the different iron atoms species is established rapidly relative to the timescale of vertical mixing in the altitude range 70 to $110 \mathrm{~km}$; and (4) the chemical lifetimes of the various species containing iron may be ignored when describing the height variation of the total concentration of iron. Under these conditions, a dynamical equilibrium is maintained by balancing the meteoric input rate against a downward flux of iron species [Helmer et al., 1998]. The following expression, proposed by Helmer et al. [1998], was used in this work in order to calculate the variation of the total iron density with height:

$$
[\mathrm{Fe}]=[\mathrm{Fe}]_{\mathrm{o}}\left(1+\Phi(\mathrm{Fe}) \int \frac{d z}{k[\mathrm{Fe}]_{\mathrm{o}}}\right)
$$

where $\Phi(\mathrm{Fe})$ is the flux of iron atoms at height $z$, based on integration of injection rate profile of meteoric iron taken from Hunten et al. [1980], and $k$ is the eddy or molecular diffusion coefficient. The parameter $[\mathrm{Fe}]_{\mathrm{o}}$ is a hypothetical profile of iron that can be obtained as the solution of the equation

$$
\frac{d[\mathrm{Fe}]}{d z}+[\mathrm{Fe}]\left(\frac{1}{H}+\frac{1}{T} \frac{d T}{d z}\right)=0
$$

for the case where the scale height of the total iron density is identical to that of the general atmosphere, $H$ [for more details see Helmer et al., 1998].

[15] Once $k, \Phi(\mathrm{Fe})$, and $[\mathrm{Fe}]_{\mathrm{o}}$ are determined as a function of altitude, equation (12) can be numerically solved to obtain the neutral density of $\mathrm{Fe}$ as a function of time and height. The eddy or molecular diffusion coefficient used in this work were taken from Danilov and Kalgin [1992]. The downward flux $\Phi(\mathrm{Fe})$ at each height is obtained by integration of the evaporation rate of meteoric atoms, $\Phi(\mathrm{Fe})=$ $\int \delta d z$, in the altitude range 86 to $140 \mathrm{~km}$. Values for $\delta$ and its variation with height are calculated using equation (11), where $\rho_{a}$ is obtained from MSISE90 model and the value of $\delta_{m}$ is taken from Carter and Forbes [1999].

\subsection{Tidal Wind}

[16] The tidal wind model used in the ionospheric model developed in this work is that described by Morton et al. [1993], where the two horizontal wind components, $U_{y}$ (eastward) and $U_{x}$ (southward) are described as follows:

$$
\begin{aligned}
& U y=U_{0 y} \exp \left(\frac{z-z_{r}}{2 H_{e}}\right) \cos \left(\frac{2 \pi}{\lambda}\left(z-z_{0}\right)+\frac{2 \pi}{P}\left(t-t_{0}\right)\right), \\
& U x=-U_{0 x} \exp \left(\frac{z-z_{r}}{2 H_{e}}\right) \sin \left(\frac{2 \pi}{\lambda}\left(z-z_{0}\right)+\frac{2 \pi}{P}\left(t-t_{0}\right)\right),
\end{aligned}
$$

where $H_{e}$ is the effective scale height for growth or decay of the tidal amplitude, with $H_{e}$ equal to $H_{e l}$ or $H_{e u}$ depending upon if $z$ is less than or greater than the reference height $z_{r}$, respectively. This wind model is characterized by the presence of nodes $(U x=0, U y=0)$ descending in height for both components. According to Morton et al. [1993], the tidal wind system over Arecibo, Puerto Rico, is characterized by a diurnal tide, which is dominant in the 80 to $100 \mathrm{~km}$ region and a semidiurnal tide which is dominant above $100 \mathrm{~km}$ altitude. Morton et al. [1993] found that a combination of diurnal, semidiurnal, and quarter-diurnal (6-hour period) tides is sufficient to explain the observed features of sporadic layers motions over Arecibo. In their work the sporadic $E$ layer dynamics is presented in the form of time-height trajectories of various peaks. When a density local maximum or peak was identified, the time and height coordinates of the peak were recorded independent of the size of the peak and independent of peaks that might be present on any other plasma density profile.

[17] In the numerical simulation of the Es layer by our ionospheric model, the coefficients used by Morton et al. [1993] have been modified to obtain results close to the Es layer frequency and height variations observed over Fortaleza in June 2001. Such modifications were implemented taking into account the fact that the tidal wind model of Morton et al. [1993] was appropriate for describing the characteristics of the sporadic $E$ layers over Arecibo and, according to classical tidal theory, the amplitudes of tidal modes are known to vary with latitude [Forbes and Lindzen, 1976; Tarpley, 1970]. The coefficients used in the present work are listed in Table 3. The main differences between the coefficients in Table 3 and those of Morton et al. [1993] are the amplitude and phase of the diurnal mode, the amplitude of the semidiurnal mode and the absence of the quarter-diurnal mode, which was present in their simulation.

\subsection{Vertical Electric Field}

[18] The electric field is one of the most important parameters of the physics of the equatorial ionosphere. The electric field structure of the equatorial ionosphere has been studied experimentally with incoherent scatter radar, rocket chemical releases, and other methods for over 3 decades. The horizontal (east-west) electric field is observed to cause the ionospheric plasma to rise during the daytime and descent during the nighttime with reversals 
Table 3. Coefficients of Wind Model Modified From Morton et al. [1993]

\begin{tabular}{cccccccccc}
\hline Tidal & Uoy & Uox & $z_{r}$ & $H_{e l}$ & $H_{e u}$ & $\lambda$ & $P$ & $z_{0}$ & $t_{0}$ \\
\hline $\mathrm{S}(1,1)$ & 30 & 18 & 95 & 10 & -11 & 19 & 24 & 100 & 23 \\
$\mathrm{~S}(2,4)$ & 1 & 1 & 95 & 8 & 200 & 55 & 12 & 110 & 7.9 \\
\hline
\end{tabular}

${ }^{\mathrm{a} U n i t s}$ are $\mathrm{m} / \mathrm{s}$ for $U_{0 y}, U_{0 x} ; \mathrm{km}$ for $z_{r}, H_{e u}, H_{e l}, z_{0}, \lambda$; hour for $t_{0}, P$.

occurring near sunset and sunrise. It is well known that just before the evening reversal the zonal electric field is often enhanced [Woodman, 1970], being identified as the PRE, discussed earlier. The mechanism of the PRE development has been discussed and modeled in several articles [Rishbeth, 1971; Farley et al., 1986; Heelis et al., 1974; Batista et al., 1986]. For example, the model by Heelis et al. [1974] has brought out the causal relation between the postsunset enhancement of the vertical velocity, or zonal electric field, and the $F$ region dynamo arising from the electrical and electrodynamical coupling between $E$ and $F$ regions. The vertical electric field development arising from the sunset electrodynamics is an inherent component of the PRE development process as mentioned before. This vertical electric field has been observed to vary strongly with altitude during the evening hours [Valenzuela et al., 1980; Tsunoda et al., 1981; Haerendel et al., 1992; Kudeki and Bhattacharyya, 1999], in a way to contribute to a plasma shear flow characterized by westward plasma drift below about $300 \mathrm{~km}$ and eastward drift above.

[19] In the absence of any observational data on the local time and height structure of the vertical electric field over Fortaleza, a model was adopted in the equatorial plane which was field-line mapped to the $E$ region over Fortaleza. For example, the electric fields at heights 150 and $200 \mathrm{~km}$ in the magnetic equatorial plane are mapped to approximately 100 and $150 \mathrm{~km}$ over Fortaleza. The equatorial vertical electric field was calculated using the following relation [Forbes, 1981]:

$$
E_{Z}=E_{y} \frac{\int \sigma_{2} d s}{\int \sigma_{1} d s}-\frac{\int \sigma_{1} U_{y} B d s}{\int \sigma_{1} d s},
$$

where $\sigma_{1}$ and $\sigma_{2}$ are the Pedersen and Hall conductivities, respectively; $B$ is the geomagnetic field intensity, $E_{y}$ is the zonal electric field (eastward positive), $U_{y}$ is the thermospheric zonal wind, and $d s$ is an element of distance along the field line. The variations in time and height of $E_{y}$ and $U_{y}$, were calculated using the $E$ and $F$ region electrical coupling model developed by Batista et al. [1986] that was based on the work by Heelis et al. [1974]. The magnetic field, $B$, was determined using the IGRF model. In the computation of $E_{z}$, the integration was extended to both hemispheres (south and north). Figure 2 shows the variation of electric field, $E_{z}$, between 1500 and $2400 \mathrm{LT}$ and for height range $150-200 \mathrm{~km}$ over the magnetic equator in Brazil. In this figure we note that $E_{z}$ has a peak around 1930 LT. The numerical values of the terms in equation (16) show that in the height region of $150-200 \mathrm{~km}$ the second term contributes little to the vertical electric field. Therefore variations in $E_{z}$ correspond essentially to the variations in $E_{y}$, which would explain the occurrence of its peak at 1930 LT. The vertical electric field so calculated is introduced into equation (10) in order to simulate the effect of such an electric field to cause the disruption of postsunset sporadic $E$ layers verified in our observational data.

\subsection{Numerical Solution}

[20] Taking into account all the model inputs described in the previous sessions, the differential equations for $\left[\mathrm{O}_{2}^{+}\right]$, $\left[\mathrm{NO}^{+}\right]$, and $\left[\mathrm{Fe}^{+}\right]$are approximated by finite differences and solved by the Crank-Nicholson method. We used $0.2 \mathrm{~km}$ grid spacing in height between 86 and $140 \mathrm{~km}$, and $15 \mathrm{~min}$ time spacing between 0000 and 2400 LT. At 0000 LT the vertical profile of each species was calculated assuming photochemical equilibrium of the species, and that profile was used as the initial condition. The contour conditions were obtained assuming no flux variation at the boundaries, that is,

$$
\frac{\partial}{\partial z}\left(V_{O_{2}^{+}}\left[O_{2}^{+}\right]\right)=0
$$

at 86 and $140 \mathrm{~km}$. The numerical equations are solved iteratively until convergence is attained.

\section{Results and Discussion}

[21] The plasma density profiles of the $E$ region were calculated using the model described above which has served us as a tool for investigating the influence of winds and electric fields on the formation of thin layers at low latitudes. In particular we will examine the separate and

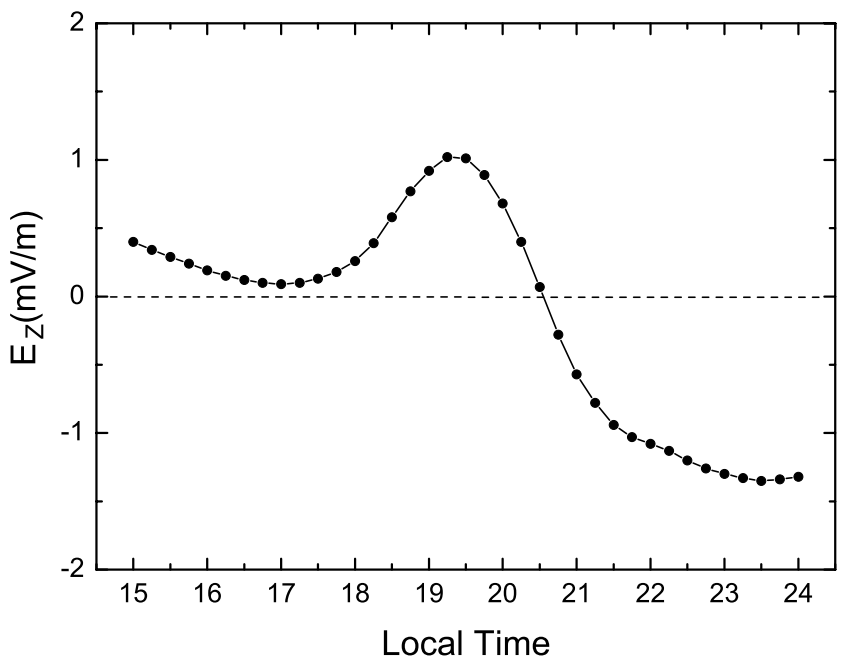

Figure 2. Temporal variation of the vertical electric field (Ez) for the height interval 150-200 km over equatorial latitudes in Brazil. 


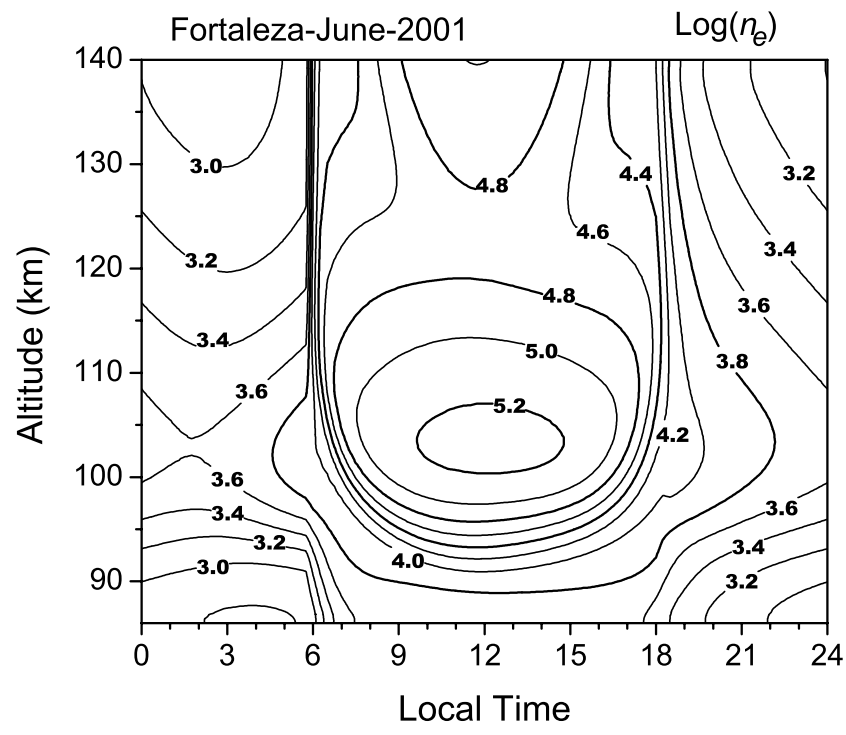

Figure 3. Contour curves of the electron density in $\log \left(n_{e}\right)$ due to chemical reactions.

combined effects of wind shear and electric fields on the collective behavior of the total ion density, including the metallic and molecular ions, in the $E$ region. We have considered several situations in the numerical simulation. In the first simulation the divergence term is considered zero in the system of equations. In the second simulation, only the contribution from tidal winds to the divergence (or transport) term is considered. In the third simulation the divergence term includes contributions from winds as well as from electric fields. From a comparison of these results we can follow the behavior step by step of the electrons density vertical profiles in this region. Under the different conditions described above, the development of sporadic $E$ layer in the background $E$ region plasma leads to different degrees of redistribution of the electron density (that is, different ratios of the peak Es layer density, indicated by $\mathrm{fbEs}$, to the background electron density).

[22] Figure 3 shows the contours of electron density variations (in logarithmic scale) in height versus local time format, as obtained from a simulation that did not take into account the transport term. In this figure we note a maximum in electron density around local noon. The electron density buildup after sunrise and decay after sunset can also be noted. Figure 4 shows the contours of electron density variation with local time in the same format as that of Figure 3 but as obtained from a simulation that included the tidal winds but no electric field. Comparing the Figures 3 and 4, we may note in Figure 4 the presence of two sporadic layers moving downward, with the electron density peak height occurring at $105 \mathrm{~km}$ and $125 \mathrm{~km}$ at local midnight. The fractional density enhancement in the sporadic $E$ layer during noon hours is found to be very small for the assumed winds due to the large background densities that prevail at these hours. The aspects such as this are of only secondary importance for the present work which concerns mainly the behavior of the sporadic layer during the postsunset hours.

[23] Figure 5 shows another perspective of Figure 4, where the sequential theoretical profiles shows two layers descending in height from 1600 LT where the peak electron

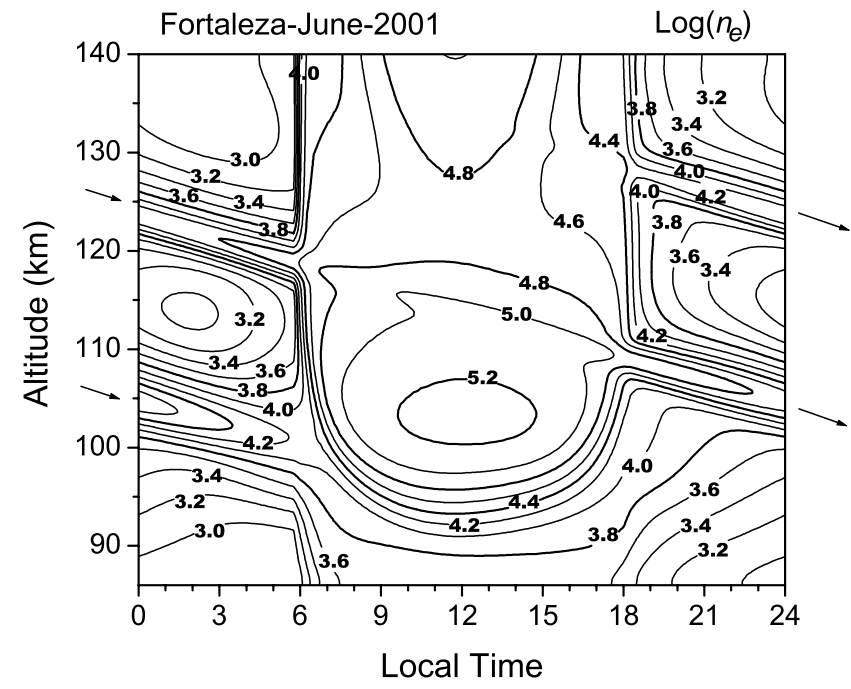

Figure 4. Contour curves of the electron density in $\log \left(n_{e}\right)$ due to tidal winds, no electric field.

density of the layers are located initially around 130 and $110 \mathrm{~km}$, respectively. The descending movement of the sporadic layer as a function of local time observed in Figures 4 and 5 are similar to that observed in the electron density profile sequence reported by Smith [1970]. The observational results by Smith [1970] over Wallops Island showed a layer at $140 \mathrm{~km}$ and its descent until $110 \mathrm{~km}$ between 0009 LT and 0602 LT at a rate of $\sim 5 \mathrm{~km} / \mathrm{hr}$ in February 1968. The layer descent rate obtained from our simulation is somewhat smaller than that observed in the data by Smith [1970] which can be attributed to the specific tidal wind model used in our calculation. Nevertheless, this comparison serves well to validate the simulation results obtained from the present $E$ region model. Many other works also report descending layers with varying descent

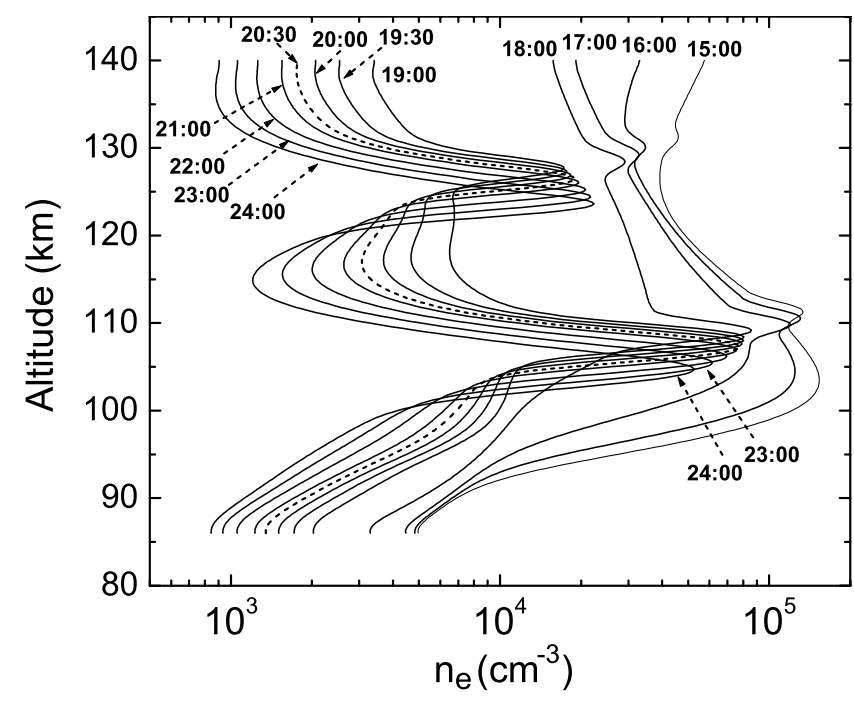

Figure 5. Altitude profiles of the electron density due to tidal winds, no electric field. The sequence of theoretical profiles shows the evolution of two sporadic layers located initially around 110 and $130 \mathrm{~km}$, respectively. 


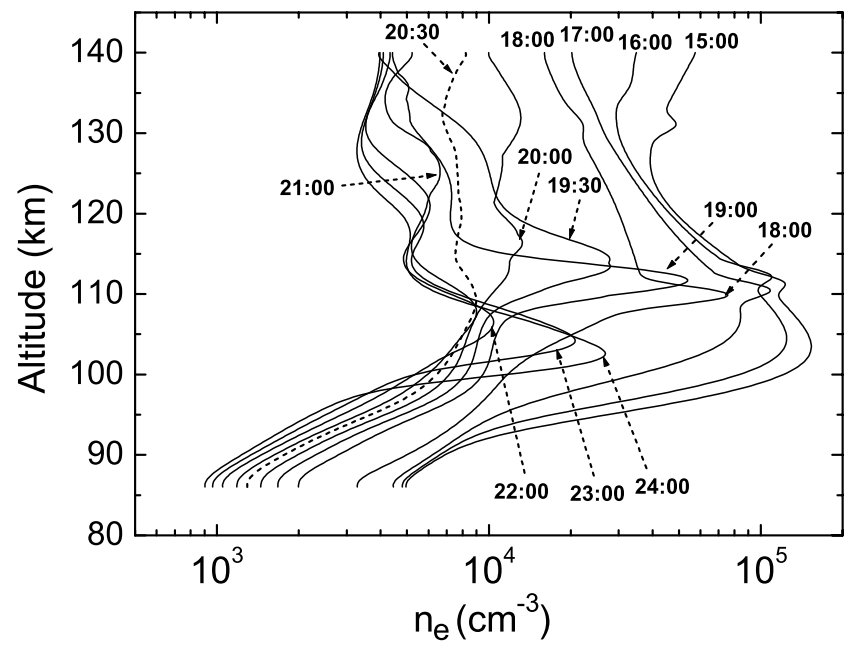

Figure 6. Altitude profiles of the electron density due to tidal winds and electric fields. The sequence of theoretical profiles shows the inhibition of the sporadic layer between 2000 and 2030 LT and its resurgence after 2100 LT.

rates [see, e.g., MacDougall et al., 2000; Wilkinson et al., 1992; Haldoupis et al., 2006].

[24] Further to the above set of simulations, the vertical electric field as obtained from equation (16) (see Figure 2) was incorporated into the model with the intention to examine the effect of this electric field on the vertical ion convergence process by wind shear mechanism. Figure 6 illustrates the effects of this electric field on the plasma density vertical distribution that are shown at 1-hour interval

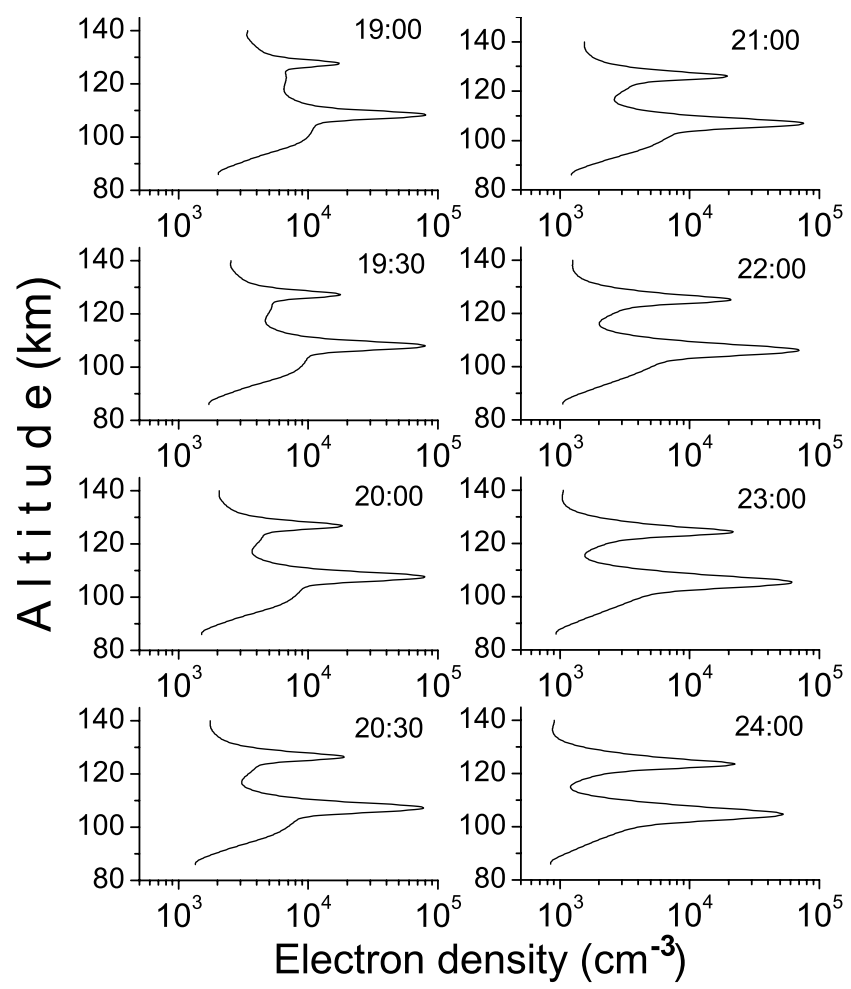

Figure 7a. Another perspective of Figure 5 (no electric field) showing individual profiles for selected local times.

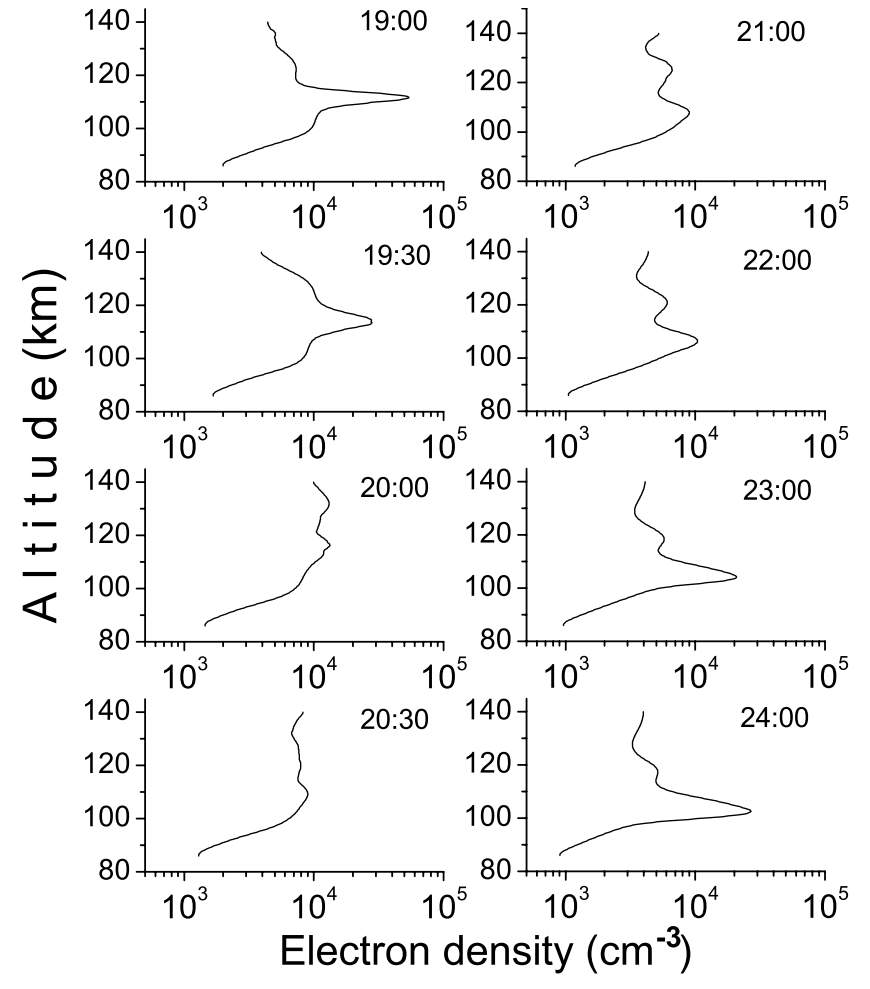

Figure 7b. Another perspective of Figure 6 (vertical electric field present) showing individual profiles for selected local times.

from 1500 LT till 2400 LT (30-min interval is used between 1900 and 2100). If we examine the consecutive electron density profiles in Figure 6, we may note that starting at 1800 LT the sporadic $E$ layer does not present any descent contrary to the generally expected behavior evident in Figures 4 and 5; instead the layer begins to rise in height under the action of the vertical electric field $E_{z}$ which is directed upward at this time. It is to be noted that at the $E$ region heights a vertical electric field is efficient to cause vertical plasma transport. In fact as shown in Figure 2 the vertical electric field is positive (upward) between 1500 and 2030 LT. The model results clearly shows the Es peak density abating to values $<2 \times 10^{4} \mathrm{el} \mathrm{cm}^{-3}$ at $2000 \mathrm{LT}$, its disruption at 2030, and the subsequent recovery starting at 2100 with peak densities $<1 \times 10^{4} \mathrm{el} \mathrm{cm}^{-3}$. In a case like that, although Es was absent only at the 2030 LT profile, the ionosonde would not register any Es from 2000 to 2200, producing an interruption/disruption as observed in Figure 1.

[25] Figures $7 \mathrm{a}$ and $7 \mathrm{~b}$ show another perspective of Figures 5 and 6 . Comparing the two figures we can see that between 1900 and 2400, under the action of the electric field (Figure $7 \mathrm{~b}$ ), the sporadic $E$ first disappears in the upper level or has much lower density than in the case under the wind shear influence only. The effect of the electric field in the lower level Es layer is more gradual. The peak density of this layer diminishes systematically until its near disappearance by 2000 and total disappearance by 2030 LT, when the peak electron density attains the level of the background $E$ region (see Figure 3). We should point out here that the precise local time of the Es layer peak density disappearance would depend upon the vertical electric field pattern of 
Figure 2 that was obtained from the model results on the zonal electric field by Batista et al. [1986] as explained earlier. As a result we expect to have certain difference between the observed and modeled times of the Es layer disruption as can be noted by comparing the results of Figures 1 and $7 \mathrm{~b}$. Even though the shearing wind continues to be active, it cannot dominate the strong influence of the vertical electric field between 1500 and 2030 hours. It is to be noted that in the plasma vertical convergence process leading to the Es layer formation the downward plasma drift arising from a westward wind has a significantly larger contribution than the upward plasma transport due to an underlying eastward wind that constitute the vertical wind shear (as explained by Abdu et al. [2003]) (this is due to the rapid height change in the Pedersen mobility in the region of the Es layer formation). Thus an upward plasma transport due to an upward directed vertical electric field should be capable of negatively influencing the vertical ion convergence needed for an Es layer formation. In other words an upward directed vertical electric field can cause disruption of an Es layer development as is indeed simulated by our model. Starting from $\sim 2030$ LT when the electric field turns negative, the situation reverses and the shearing wind takes better control of the plasma convergence process. During these hours the downward electric field contributes positively to the vertical ion convergence process driven by the wind shear mechanism. The sporadic layer that resurges (as a result) at $108 \mathrm{~km}$ and $2130 \mathrm{LT}$ descends until $103 \mathrm{~km}$ with its peak density steadily increasing.

[26] The present simulation is not intended to constitute a case study due to our limited knowledge on the precise magnitudes and phases of the key factors that affects the Es layer formation such as the tidal winds and vertical electric fields that are representative of the observational conditions. Although we have used reasonable models for them, we do not expect a perfect agreement between model and observations, but with this simulation we were able to show that the results are consistent with the observations (Figure 1) where the sporadic layer presents the phases of abating or disruption and resurgence between 1900 and 2200 LT. Additionally, these results provide a quantitative corroboration of the explanation given by Abdu et al. [2003] that the disruption of the post sunset sporadic $E$ layers over Fortaleza (and now also over São Luís) in association with larger intensity of the prereversal electric field enhancement is caused by the vertical electric field enhancement that accompanies the PRE development. It is opportune to point out here that the mere presence of a sporadic $E$ layer in the evening $E$ region that is capable of modifying the longitudinal/local time gradient in the $E$ layer integrated Pedersen conductivity could influence the intensity of the PRE development as shown by Carrasco et al. [2005] in addition to influencing (diminishing) the Rayleigh-Taylor instability growth rate for the generation of the equatorial spread $F$ as shown by Stephan et al. [2002]. Nevertheless, our observational results supported by the present model simulation results would suggest that the phenomenon of Es layer disruption and the subsequent resumption, in association with the development of the evening prereversal enhancement electric field, that is often observed at a latitude in the immediate vicinity of the dip equator, is an important element of the sunset electrodynamic process of the equatorial region.

\section{Conclusions}

[27] We have developed a computational model for lowlatitude quiet time $E$ region that provides the electron density height distribution as function of local time. The model takes into account all the major photochemical processes, including the chemistry of both the major molecular and metallic ions species and the plasma transport by diurnal and semidiurnal tidal winds and by vertical electric field. The objective of the study is to investigate the development of sporadic $E$ layers of the low-latitude $E$ region with specific focus on the influence of the sunset electrodynamic processes in the formation and intensity of the Es layers during post sunset hours. Observational results presented in this work and our previous studies have shown that sporadic $E$ layer formation after sunset can be disrupted at the evening uplift of the $F$ layer arising from the development of the prereversal electric field enhancement by $F$ layer dynamo process. The disrupted $E s$ layer has been observed to form again after an interval of 2-3 hours. The model result shows that a vertical electric field can significantly influence the ion convergence process for the formation of sporadic $E$ layer primarily driven by wind shear mechanism. An upward directed vertical electric field can cause interruption of the ion convergence while a downward directed electric field can contribute to it. Using model results to represent the evening vertical electric field development, we have shown that the post sunset enhancement in this electric field, which constitutes the conditions for the evening prereversal zonal electric field enhancement, is indeed capable of causing the disruption of the Es layer formation verified in our observations. The modeled local time variation pattern of this vertical electric field is also capable of explaining the resumption of the Es layer formation, following the disruption, as observed. These results thus corroborate the mechanism earlier proposed by $A b d u$ et al. [2003] connecting the Es layer disruption and the PRE development. In view of the well known and rather direct association between the PRE and the development of the equatorial spread $F$, the new evidence on the association between the PRE and sporadic $E$ layer on the one hand and a possible expected relationship between the ESF and sporadic $E$ layer on the other, does present new challenging questions in the continuing research for causes of the widely known day-to-day variability in the equatorial spread $F$ development.

[28] Acknowledgments. The authors wish to acknowledge the supports from FAPESP through the project 1999/00437-0, CNPq through grants 502804/2004-1 and 500271/2003-8. One of the authors (AJC) wishes to acknowledge CAPES for the fellowship during the development of this research.

[29] Wolfgang Baumjohann thanks Christos Haldoupis and two other reviewers for their assistance in evaluating this paper.

\section{References}

Abdu, M. A., I. S. Batista, P. Muralikrishna, and J. H. A. Sobral (1996), Long-term trends in sporadic $E$ layers and electric fields over Fortaleza, Brazil, Geophys. Res. Lett., 23, 757-760.

Abdu, M. A., J. MacDougall, I. S. Batista, J. H. A. Sobral, and P. T. Jayachandran (2003), Equatorial evening prereversal electric field enhancement and sporadic $E$ layer disruption: A manifestation of $E$ and 
$F$ region coupling, J. Geophys. Res., 108(A6), 1254, doi:10.1029/ 2002JA009285.

Aikin, A. C., and R. A. Goldberg (1973), Metallic ions in the equatorial ionosphere, J. Geophys. Res., 78, 734-745.

Axford, W. I. (1963), The formation and vertical movement of dense ionized layers in the ionosphere due to neutral wind shears, J. Geophys. Res., 68 $769-779$

Bailey, G. J., and N. Balan (1996), A low-latitude ionosphere-plasmasphere model, in STEP Hand Book of Ionospheric Models, edited by R. W Schunk, pp. 173-206, Utah State Univ., Logan.

Barth, C. A., C. B. Farmer, D. E. Siskind, and J. P. Perich (1996), ATMOS observations of nitric oxide in the thermosphere, J. Geophys. Res., 101 , $12,489-12,494$

Batista, I. S., M. A. Abdu, and J. A. Bittencourt (1986), Equatorial F region vertical plasma drift: Seasonal and longitudinal asymmetries in the American sector, J. Geophys. Res., 91, 12,055-12,064.

Bittencourt, J. A., and M. A. Abdu (1981), Theoretical comparison between apparent and real vertical ionization drift velocities in the equatorial F region, J. Geophys. Res., 86, 2451-2454.

Carrasco, A. J., I. S. Batista, and M. A. Abdu (2005), The pre-reversa enhancement in the vertical drift for Fortaleza and the sporadic $E$ layer, J. Atmos. Sol. Terr. Phys., 67, 1610-1617.

Carter, L. N., and J. M. Forbes (1999), Global transport and localized layering of metallic ions in the upper atmosphere, Ann. Geophys., 17, $190-209$

Chen, W. M., and R. D. Harris (1971), An ionospheric E-region nighttime model, J. Atmos. Terr. Phys., 33, 1193-1207.

Danilov, A. D., and U. A. Kalgin (1992), Seasonal and latitudinal variations of eddy diffusion coefficient in the mesosphere and lower thermosphere, J. Atmos. Terr. Phys., 54, 1481-1489.

Eccles, J. V. (1998), Modeling investigation of the evening prereversal enhancement of the zonal electric field in the equatorial ionosphere, J. Geophys. Res., 103, 26,709-26,719.

Farley, D. T., E. Bonelli, B. G. Fejer, and M. F. Larsen (1986), The prereversal enhancement of the zonal electric field in the equatorial ionosphere, J. Geophys. Res., 91, 13,723-13,728.

Forbes, J. M. (1981), The equatorial electrojet, Rev. Geophys., 19, 469504

Forbes, J. M., and R. S. Lindzen (1976), Atmospheric solar tides and their electrodynamic effects, I, The global Sq current system, J. Atmos. Tern Phys., 38, 897-910

Haerendel, G., J. V. Eccles, and S. Çakir (1992), Theory of modeling the equatorial evening ionosphere and the origin of the shear in the horizontal plasma flow, J. Geophys. Res, 97, 1209-1223.

Haldoupis, C., C. Meek, N. Christakis, D. Pancheva, and A. Bourdillon (2006), Ionogram height-time-intensity observations of descending sporadic E layers at mid-latitude, J. Atmos. Sol. Terr. Phys., 68, 539-557.

Hedin, A. E. (1991), Extension of the MSIS thermosphere model into the middle and lower atmosphere, J. Geophys. Res., 96, 1159-1172.

Heelis, R. A. (1999), Ionization layers observed at middle latitudes by atmosphere Explorer-C, J. Atmos. Solar Terr. Phys., 61, 407-414.

Heelis, R. A., P. C. Kendall, R. J. Moffett, D. W. Windle, and H. Rishbeth (1974), Electrical coupling of the E and F regions and its effects on F region drifts and winds, Planet. Space Sci., 22, 743-756.

Helmer, M., J. M. Plane, J. Qian, and C. S. Gardner (1998), A model of meteoric iron in the upper atmosphere, J. Geophys. Res., 103, 10,91310,925 .

Hunten, D. M., R. P. Turco, and O. B. Toon (1980), Smoke and dust particles of meteoric origin in the mesosphere and stratosphere, J. Atmos. Sci., 37, 1342-1357.

Jones, J., and T. R. Kaiser (1966), The effects of thermal radiation, conduction and meteoroid heat capacity on meteoric ablation, Mon. Not. R. Astron. Soc., 133, 411-420.
Kopp, E. (1997), On the abundance of metal ions in the lower ionosphere, J. Geophys. Res., 102, 9667-9674.

Korenkov, Y. N. (1979), Effect of motions in the neutral atmosphere on the seasonal-daily behavior of the Es layer, Geomagn. Aeron., 19, 15-19.

Kudeki, E., and S. Bhattacharyya (1999), Post sunset vortex in equatorial $F$-region plasma drifts and implications for bottom side spread $\mathrm{F}$, J. Geophys. Res., 104, 28,163-28,170.

Layzer, D. (1972), Theory of midlatitude sporadic E, Radio Sci., 7, $385-$ 395

MacDougall, J. W., J. M. C. Plane, and P. T. Jayachandran (2000), Polar cap sporadic-E: part 2, Modeling, J. Atmos. Sol. Terr. Phys., 62, 1169

Miller, N. J., J. M. Grebowsky, A. E. Hedin, and N. M. Spencer (1993), Equatorial ion composition, $140-200 \mathrm{~km}$, based on atmosphere Explorer E, data, J. Geophys. Res., 98, 685-692.

Morton, Y. T., J. D. Mathews, and Q. Zhou (1993), Further evidence for a 6-h tide above Arecibo, J. Atmos. Terr. Phys., 55, 459-465.

Narcisi, R. S. (1967), Processes associated with metal-ion layers in the $E$ region of the ionosphere, Space Res., 8, 360-369.

Rees, M. H. (1989), Physics and Chemistry of the Upper Atmosphere, Cambridge Univ. Press, Cambridge, U. K.

Richards, P. G., J. A. Fennelly, and D. G. Torr (1994), EUVAC: A solar EUV flux model aeronomic calculations, J. Geophys. Res., 99, 89818992.

Rishbeth, H. (1971), Polarization fields produced by winds in the equatorial F-region, Planet. Space Sci., 19, 357-369.

Shen, J. S., W. E. Swartz, and D. T. Farley (1976), Ionization layers in the nighttime $E$ region valley above Arecibo, J. Geophys. Res., 81, 55175526.

Smith, L. G. (1970), A sequence of rocket observations of night-time sporadic-E, J. Atmos. Terr. Phys., 32, 1247-1257.

Stephan, A. W., M. Colerico, M. Mendilo, B. W. Reinisch, and D. Anderson (2002), Suppression of equatorial spread $F$ by sporadic E, J. Geophys. Res., 107(A2), 1021, doi:10.1029/2001JA000162.

Strobel, D. F., T. R. Young, R. R. Meier, T. P. Coffey, and A. W. Ali (1974), The nighttime ionosphere $E$ region and lower $F$ region, J. Geophys. Res. 79, 3171-3178.

Tarpley, J. D. (1970), The ionospheric wind dynamo-II-Solar tides, Planet. Space Sci., 18, 1091-1103.

Tsunoda, R. T., R. C. Livingston, and C. L. Rino (1981), Evidence of a velocity shear in bulk plasma motion associated with the post-sunset rise of the equatorial F-layer, Geophys. Res. Lett., 7, 807-810.

Turunen, E., H. Matveinen, J. Tolvanen, and H. Ranta (1996), D-region ion chemistry model, in STEP Hand Book of Ionospheric Models, edited by R. W. Schunk, pp. 1-25, Utah State Univ., Logan.

Valenzuela, A., G. Haerendel, A. Foppl, E. Reiger, B. G. Fejer, and M. C. Kelley (1980), Incoherent scatter radar and barium cloud measurements of electric fields in the equatorial zone, Eos Trans. AGU, 61, 315

Whitehead, J. D. (1961), The formation of the sporadic-E layer in the temperate zones, J. Atmos. Terr. Phys., 20, 49-58.

Wilkinson, P. J., E. P. Szuszczewicz, and R. G. Roble (1992), Measurements and modeling of intermediate, descending, and sporadic layers in the lower ionosphere: results and implications for global-scale ionospheric-thermospheric studies, Geophys. Res. Lett., 19, 95.

Woodman, R. F. (1970), Vertical drift velocities and east-west electric fields at the magnetic equator, J. Geophys. Res., 75, 6249-6259.

M. A. Abdu and I. S. Batista, Instituto Nacional de Pesquisas Espaciais, São José dos Campos, Av. dos Astronautas 1758, Cx. Postal 515, SP 12201-970, Brazil. (maabdu@dae.inpe.br; inez@dae.inpe.br)

A. J. Carrasco, Departamento de Física, Universidad de Los Andes, Sector La Hechicera, Zona Postal 5105, Mérida, Venezuela. (carrasco@ ula.ve) 